\title{
Long-term renal graft outcome after parathyroidectomy - a retrospective single centre study
}

\author{
Margret Patecki ${ }^{*}$, Irina Scheffner, Hermann Haller and Wilfried Gwinner
}

\begin{abstract}
Background: Surgical correction of hyperparathyroidism after kidney transplantation has been associated with significant graft function decline. We examined the effects of parathyroidectomy on short- and long-term graft function and its potential predictors.

Methods: For this retrospective, monocentric study we identified 48 (5.5\%) out of 892 patients from our protocol biopsy program who received renal transplantation between 2000 and 2007, with parathyroidectomy after transplantation. Data from up to three years after parathyroidectomy was collected and analyzed with multivariable linear regression analyses.

Results: Main indications for parathyroidectomy were hypercalcemia and graft calcifications. Parathyroidectomy was successful in 47 patients, with a median drop in serum intact parathormone (iPTH) from 394 to $21 \mathrm{pg} / \mathrm{ml}$. Mean estimated glomerular fitration rate (eGFR) before parathyroidectomy was $60 \pm 26 \mathrm{ml} / \mathrm{min}$. At three months after parathyroidectomy, the eGFR was $46 \pm 18 \mathrm{ml} / \mathrm{min}(p<0.001)$ but remained stable at one and three years $(50 \pm 20 ; 49 \pm$ $20 \mathrm{ml} / \mathrm{min}$ ). The median annual eGFR change was $-0.5 \mathrm{ml} / \mathrm{min}$ before and $+1.0 \mathrm{ml} / \mathrm{min}$ after parathyroidectomy. Multivariable modeling identified high iPTH levels and higher eGFR before parathyroidectomy as predictors of the eGFR drop after parathyroidectomy. Lower graft function twelve months after parathyroidectomy was predicted by the eGFR before and the iPTH drop after surgery.

Conclusions: These results indicate that the extent of parathyroidectomy is critical and too much lowering of iPTH should be avoided by timely parathyroidectomy, before reaching extreme high iPTH values. In view of the observed loss of eGFR, parathyroidectomy can be considered safe in patients with an eGFR above $30 \mathrm{ml} / \mathrm{min}$.
\end{abstract}

Keywords: Renal transplantation, Parathyroidectomy, Hyperparathyroidism, Hypercalcemia, Kidney function

\section{Background}

Persisting or even worsening hyperparathyroidism after kidney transplantation affects between 17 and 50\% [1-5] of the transplant population and can lead to worsening graft function, bone disease and extraskeletal calcifications [1, 6-10]. Despite its off-label character, calcimimetics are increasingly used in this condition to control serum calcium and parathormone levels [11]. Nevertheless, the long-term consequences on bone metabolism are unknown $[12,13]$ and side effects or lacking efficacy are frequent problems. These patients may benefit from

\footnotetext{
* Correspondence: patecki.margret@mh-hannover.de Department of Nephrology and Hypertension, Hannover Medical School, Carl-Neuberg-Straße 1, 30635 Hannover, Germany
}

parathyroidectomy which is reported with rates of about $5 \%$ in the transplant population, thus avoiding the above mentioned complications $[1,7,14]$.

Previous studies have reported differing results of parathyroidectomy after kidney transplantation. Although regarded as an efficient treatment, concerns have been raised that parathyroidectomy adversely affects the graft. In the retrospective study of Schwarz et al. a decrease in creatinine clearance by $10 \%$ was reported, without relevant recovery during a 12-month follow-up [15]. Evenepoel et al. also reported an increase in serum creatinine by $16 \%$ in the first 6 months after parathyroidectomy, with partial reversal and stabilization of graft function in the long term over 4 years [16]. In another

(C) The Author(s). 2020 Open Access This article is distributed under the terms of the Creative Commons Attribution 4.0 International License (http://creativecommons.org/licenses/by/4.0/), which permits unrestricted use, distribution, and 
study, patients with parathyroidectomy had 6-year graft survival of less than $15 \%$, whereas patients without had a graft survival of approximately $70 \%$. However, in the multivariable analysis, parathyroidectomy was not a significant factor [17].

Currently, it is not possible to predict which patient will suffer from a temporary or persistent decline in graft function after parathyroidectomy. To this end, (i) a greater iPTH drop (ii) lower serum calcium, (iii) and requirement for more intense substitution with calcium and vitamin D analogues for hypocalcemia after parathyroidectomy, (iv) lower baseline creatinine before parathyroidectomy, (v) and the time interval between parathyroidectomy and transplantation have been inconsistently reported as potential factors of a declining renal function after parathyroidectomy $[3,15,18,19]$. Furthermore, the effects of different extents of parathyroid tissue resection on the graft function are still under discussion $[15,19,20]$.

Aims of this study were to examine the effect of parathyroidectomy on the graft function and to explore potential determinants of the loss of transplant function and recovery in a well-documented patient cohort with protocol biopsies and long-term follow-up.

\section{Methods}

\section{Patients}

In this retrospective study, adult patients were included who received a kidney transplant alone or in combination with another solid organ at Hannover Medical School between 2000 and 2007 and who participated in our protocol biopsy program. Protocol biopsies were performed 6 weeks, 3 and 6 months after transplantation. Data were collected prior to and at the time of transplantation, at the time points of protocol biopsies and any additional biopsies, and in yearly intervals after transplantation. For patients who were followed-up elsewhere, data were retrieved by contacting their local caregivers. Data collection and analysis was performed with informed consent of the patients and with approval of the ethic board (no 2765) of the Hannover Medical School.

\section{Methods}

Renal function was assessed by the estimated glomerular filtration rate using the Cockcroft\&Gault formula. All parathormone levels were analyzed as intact PTH (normal limits: $10-65 \mathrm{pg} / \mathrm{mL}$; Advia Centauer System, Siemens Corp., Germany). Serum calcium and phosphate levels were determined by an autoanalyzer of the hospital's laboratory (normal ranges: $2.15-2.60 \mathrm{mmol} / \mathrm{L} ; 0.73-$ $1.35 \mathrm{mmol} / \mathrm{L}$, respectively), without correcting serum calcium for albumin concentrations. Delayed graft function was defined as urine output of less than $500 \mathrm{ml}$ in the first $24 \mathrm{~h}$ after transplantation and/or need of dialysis because of graft dysfunction within the first week after transplantation. Biopsies were evaluated according to the Banff classification. Besides routine stainings, von Kossa stain was performed on those cases which had tubular or interstitial crystalloid deposits [21]. Calcifications were roughly characterized as 'mild' with up to 2 foci of crystalloid deposits per microscopic section of the biopsy at 200fold magnification and 'severe' with $>2$ foci. There was no specific medical treatment for calcification. Rejections were treated as reported elsewhere in detail [22].

\section{Statistical analysis}

The IBM SPSS statistical software package version 24 was used for statistical analysis. Continuous variables with normal distribution are given as means $\pm \mathrm{SD}$, data without normal distribution as medians. Continuous data were compared with the Kruskal-Wallis and MannWhitney test. The Spearman rank test was used for correlation analyses. Kaplan-Meier analysis and the logrank test were used to compare graft survival of patients with and without parathyroidectomy. Multivariable linear regression analyses were performed to assess the effect of clinical and laboratory factors on eGFR, using backward selection and a cutoff $p$ value of $<0.05$. Alternative models using forward selection or no variable selection were tested in comparison. Variables chosen for the multivariable modeling were selected from Table 2, using a cutoff $p$ value of $<0.15$, but excluding variables with redundant information (such as serial eGFR measurements) or variables with clear causality secondary to another, significant variable (e.g. low serum phosphate caused by parathormone). Further, the large list of candidate variables shown in Table 2 and Additional file 1 was thoroughly examined for variables with potential bearing on parathyroidectomy associated adverse effects on graft, even without showing a $p$ value of $<0.15$. Statistical significance was assumed for $p<0.05$.

\section{Results}

In a cohort of 892 patients in our database who were transplanted between 2000 and 2007, 48 patients (5.4\%; $n=23$ female, $n=25$ male) were identified with parathyroidectomy after kidney transplantation. Pretransplant and perioperative data of these patients are depicted in Table 1. Five patients had their second kidney transplantation. Three patients received combined pancreas and kidney transplantation. Delayed graft function occurred in 14 patients $(29 \%) .40$ patients $(83 \%)$ received a graft from a deceased donor. Low parathormone levels in the year before transplantation, defined as parathormone levels below 2.5 times above the upper normal value were observed in only three patients. The highest eGFR within the first 6 months after transplantation was 
Table 1 Description of patients

\begin{tabular}{|c|c|}
\hline Age (mean $\pm S D)$ & $47.7 \pm 11.4$ \\
\hline Gender (male/female) & $\begin{array}{l}25 / 23(52.1 / \\
47.9)\end{array}$ \\
\hline $\begin{array}{l}\text { Renal replacement therapy before transplantation } \\
\text { hemodialysis / peritoneal dialysis }\end{array}$ & 44 / $4(91.7$ / 8.3) \\
\hline Time on dialysis (months; mean \pm SD) & $78.7 \pm 32.8$ \\
\hline Body mass index at transplantation (mean \pm SD) & $24.2 \pm 3.7$ \\
\hline \multicolumn{2}{|l|}{ Transplantation data } \\
\hline Donor serum creatinine $(\mu \mathrm{mol} / \mathrm{l}$; mean $\pm \mathrm{SD})$ & $80.1 \pm 36.5$ \\
\hline Donor age (mean \pm SD) & $45 \pm 17$ \\
\hline Donor gender (male; female) & $20(43) / 27(57)$ \\
\hline $\begin{array}{l}\text { Heterogeneous / homogeneous donor/recipient } \\
\text { gender (female donor / male donor) }\end{array}$ & $\begin{array}{l}20(13 / 7) / 26(15 \\
/ 11)\end{array}$ \\
\hline Second or third kidney transplantation & $5(10.4)$ \\
\hline Additional pancreas transplantation & $3(6.3)$ \\
\hline Living donor transplantation & $8(16.7)$ \\
\hline Eurotransplant Senior Program & $1(2)$ \\
\hline Pre-formed antibodies > $\%$ & $3(6)$ \\
\hline Mean number of HLA mismatches (A/B/DR) & $2.21 \pm 1.3$ \\
\hline Cold ischemic time (hours; mean \pm SD) & $16.3 \pm 9.5$ \\
\hline Delayed graft function & $14(29.2)$ \\
\hline CMV IgG positive recipient & $26(55)$ \\
\hline Donor CMV IgG positive & $25(53)$ \\
\hline \multicolumn{2}{|l|}{ Immunosuppressive therapy } \\
\hline $\begin{array}{l}\text { Induction therapy: IL-2 AB / ATG / none / } \\
\text { unknown }\end{array}$ & $\begin{array}{l}38 / 3 / 6 / 1 \\
(79.2 / 6.3 / 12.5 / \\
2.1)\end{array}$ \\
\hline Ciclosporin A & $35(72.9)$ \\
\hline Tacrolimus & $9(18.8)$ \\
\hline Mycophenolate mofetil & $30(62.5)$ \\
\hline Rapamycin & $4(8.3)$ \\
\hline Steroids & $46(95.8)$ \\
\hline \multicolumn{2}{|l|}{ Main reason for ESRF } \\
\hline Unknown & $17(35.4)$ \\
\hline Glomerulonephritis & $15(31.3)$ \\
\hline Tubulointerstitial disease & $4(8.3)$ \\
\hline Hypertensive or diabetic nephropathy & $3(6.3)$ \\
\hline Congenital disease & $8(16.7)$ \\
\hline Other & $1(2.1)$ \\
\hline \multicolumn{2}{|l|}{ Comorbidities before or at transplantation } \\
\hline Heart failure & $1(2)$ \\
\hline Hypertension & $46(95.8)$ \\
\hline Peripheral arterial disease & $5(10.4)$ \\
\hline Coronary heart disease & $4(8.3)$ \\
\hline Stroke & $1(2.1)$ \\
\hline Hepatitis C & $2(4.2)$ \\
\hline Diabetes type I / || & $4(8.3) / 1(2.1)$ \\
\hline
\end{tabular}

Table 1 Description of patients (Continued)

$\begin{array}{ll}\text { Hypercholesterolemia } & 20(41.7) \\ \text { Smoking still present / given up / never / } & 4 / 11 \text { / 25 / 8 } \\ \text { unknown } & (8.3 / 22.9 \text { / } 52.1 / \\ & 16.7) \\ \text { Pregnancies before actual transplantation } & 19(40) \\ \text { Blood transfusions before transplantation } & 14(30)\end{array}$

Proportions are depicted as number of patients, with percentages in brackets ATG Anti-thymocyte globulin, CMV Cytomegalovirus, ESRF End stage renal failure, $H L A$ human leukocyte antigen, IL-2 $A B$ Interleukin-2 antibodies, $S D$ Standard deviation

$67 \pm 25 \mathrm{ml} / \mathrm{min}$. Five patients were on therapy with cinacalcet, seven patients were treated with bisphosphonates, and one patient with calcitonin directly before parathyroidectomy.

Parathyroidectomy was intended as subtotal resection in 14 cases, as total resection with auto-transplantation in 28 cases, and as total resection without auto-transplantation in 4 cases; in 2 patients further information was not available. Five patients had recurrent hyperparathyroidism after parathyroidectomy performed before transplantation. In one patient, two parathyreoidectomies after transplantation were necessary. The median time between transplantation and parathyroidectomy was 19.5 months (range: 4-80 months), with 15 patients receiving the parathyroidectomy within the first year, 17 patients within the second year, and 15 patients after the second year posttransplantation. Main indication for parathyroidectomy was repeated hypercalcemia due to hyperparathyroidism not responsive to medical management $(n=34 ; 71 \%)$. Calcification in the renal graft (in one or more preceding biopsies) in the presence of high serum calcium and/or elevated parathormone levels was another reason for parathyroidectomy in 31 (65\%) patients. Calcification was observed as single finding in one biopsy in 14 patients, in two biopsies in 14 patients and in 3 biopsies in 3 patients. 19 cases had mild calcification and 8 severe calcifications and four were without grading.

The post-transplant course of parathormone and serum calcium values is shown in Figs. 1 and 2. At 6 weeks, the median iPTH was $296 \mathrm{pg} / \mathrm{ml}$ (range: $57-1028 \mathrm{pg} / \mathrm{ml}$ ) and $385 \mathrm{pg} / \mathrm{ml}$ (range: $31-1780 \mathrm{pg} / \mathrm{ml}$ ) at 6 months. Mean serum calcium levels at 6 weeks after transplantation were $2.53 \pm 0.21 \mathrm{mmol} / \mathrm{l}$ (normal range: $2.15-2.6 \mathrm{mmol} / \mathrm{l}$ ) and $2.65 \pm 0.17 \mathrm{mmol} / \mathrm{l}$ at 6 months. Mean serum phosphate levels were $0.63 \pm 0.29$ (normal range: $0.73-1.35 \mathrm{mmol} / \mathrm{l}$ ) and $0.94 \pm 0.27 \mathrm{mmol} / \mathrm{l}$ at 6 weeks and 6 months posttransplantation, respectively (not shown). Directly before parathyroidectomy, median iPTH was $394 \mathrm{pg} / \mathrm{ml}$ (range: $71-1699 \mathrm{pg} / \mathrm{ml}$ ), mean serum calcium $2.63 \pm 0.20 \mathrm{mmol} / \mathrm{l}$, and phosphate $0.89 \pm 0.26 \mathrm{mmol} / \mathrm{l}$. One patient had hypocalcemia due to a high dose of cinacalcet at this time. iPTH values showed a weak inverse correlation with 
Patecki et al. BMC Nephology

(2020) 21:53

Page 4 of 10

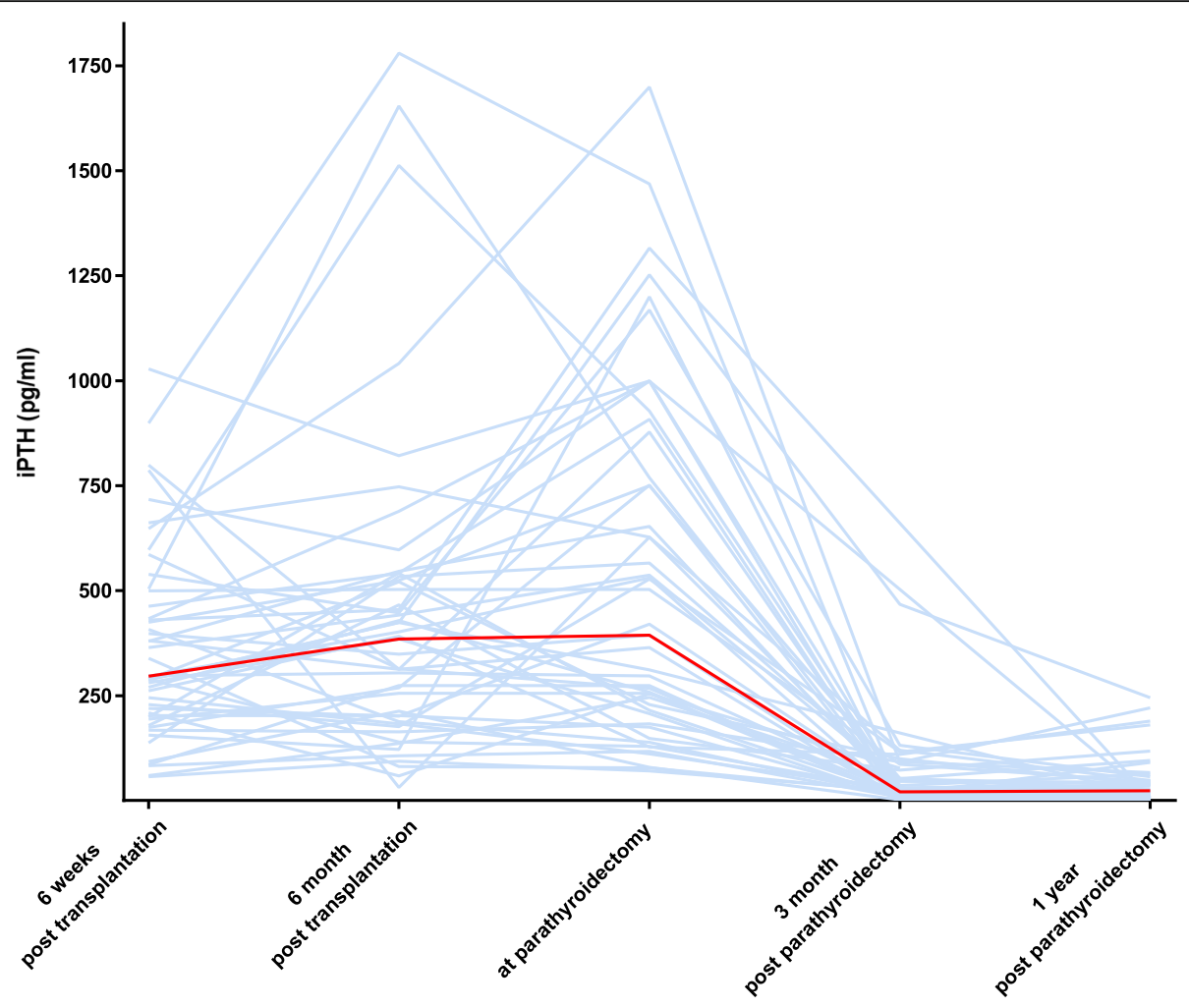

Fig. 1 Intact parathormone levels before and after parathyroidectomy. Blue lines represent individual values; the red line represents the median course of all patients. IPTH; intact parathormone

serum calcium $(\mathrm{r}=-0.36 ; p<0.05)$ at this time. This correlation was not observed at 6 weeks and 6 months posttransplantation (Fig. 3). Serum phosphate correlated with iPTH levels, with $r=-0.33$ at 6 weeks and $r=-0.32$ at 6 months $(\mathrm{p}<0.05)$ (not shown).
At 3 months after parathyroidectomy, iPTH values had dropped in all patients, showing a median of $21 \mathrm{pg} / \mathrm{ml}$ (range: $1-467 \mathrm{pg} / \mathrm{ml}$ ) (Fig. 1). For three patients there were no iPTH values available at 3 months after parathyroidectomy. In twenty-three patients (48\%) iPTH values

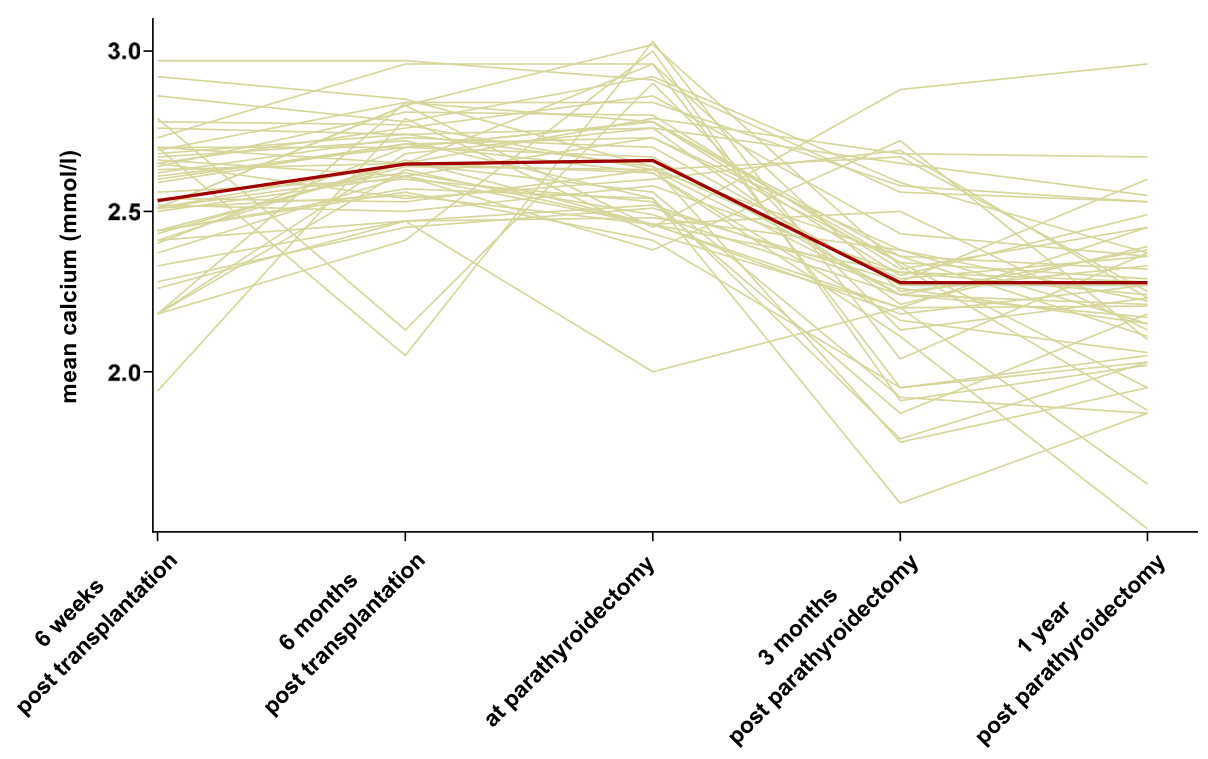

Fig. 2 Serum calcium before and after parathyroidectomy. Green lines represent individual values; the red line represents the mean 

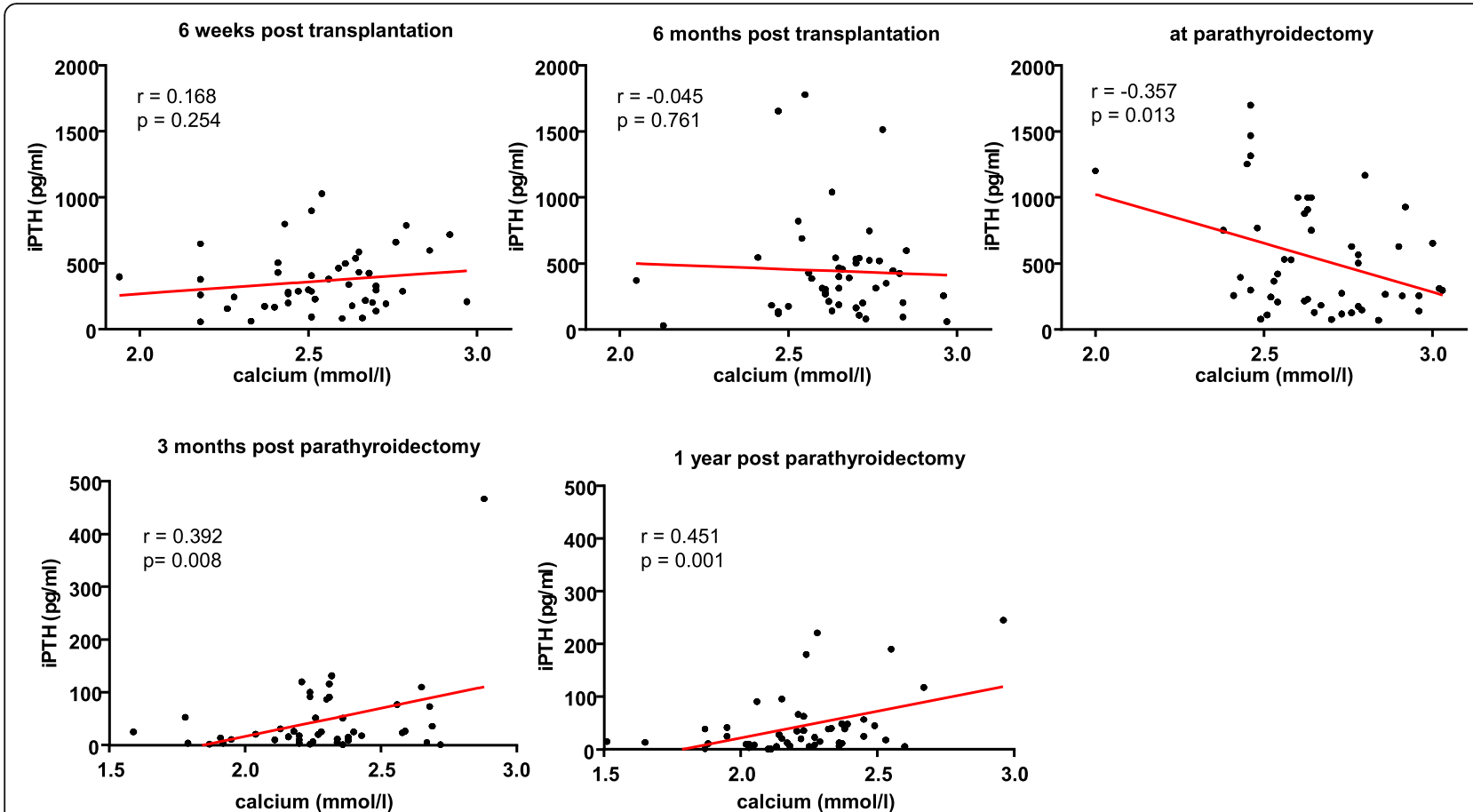

Fig. 3 Correlation between parathormone levels and serum calcium before and after parathyroidectomy. Note different scales for iPTH values pre- and post-parathyroidectomy. iPTH; intact parathormone

were in the normal range of $10-65 \mathrm{pg} / \mathrm{ml}$, in eleven patients $(23 \%)$ below the lower normal, and eleven patients (23\%) had iPTH values between the upper normal and $300 \mathrm{pg} / \mathrm{ml}$. One year after parathyroidectomy, median $\mathrm{iPTH}$ was $24 \mathrm{pg} / \mathrm{ml}$ (range: $1-245 \mathrm{pg} / \mathrm{ml}$ ) and mean serum calcium was $2.23 \pm 0.26 \mathrm{mmol} / \mathrm{l}$. Calcium and parathormone levels were moderately correlated after parathyroidectomy (Fig. 3). Serum calcium fell in most patients, with an average of $2.29 \pm 0.27 \mathrm{mmol} / \mathrm{l}$ at 3 months after parathyroidectomy (Fig. 2), and phosphate rose to $1.16 \pm 0.35 \mathrm{mmol} / \mathrm{l}$. Hypercalcemia above 2.6 $\mathrm{mmol} / \mathrm{l}$ was present in only 3 patients $(6.3 \%)$. Hypocalcemia below $2.15 \mathrm{mmol} / \mathrm{l}$ occurred in eleven patients (23\%). At one year after parathyroidectomy, 16 patients had calcium supplements, 37 patients had calcitriol or calcidiol and 2 patients colecalciferol to maintain calcium homeostasis. None of the patients received cinacalcet.

The changes in estimated eGFR are shown in Fig. 4. Directly before parathyroidectomy the mean eGFR was $60 \pm 26 \mathrm{ml} / \mathrm{min}$. Within the first 3 months, the eGFR dropped to $46 \pm 18 \mathrm{ml} / \mathrm{min}(p<0.001)$ but remained stable at one and three years after parathyroidectomy $(50 \pm 20 ; 49 \pm 20 \mathrm{ml} / \mathrm{min}$ ) (Fig. 4). There were no graft losses during follow-up of three years after parathyroidectomy. The median annual eGFR change was $-0.5 \mathrm{ml} / \mathrm{min}$ before and $+1.0 \mathrm{ml} / \mathrm{min}$ in the time interval between parathyroidectomy and the following 3 years. For comparison, overall 15-year death-censored graft survival and eGFR decline were similar to that of the 844 patients who had not undergone parathyroidectomy (cumulative survival of 76 vs. $71 \%, p=0.356$; median annual loss of eGFR of -2.47 vs. $-2.05 \mathrm{ml} / \mathrm{min}, p=0.877$; for patients with and without parathyroidectomy).

In a comprehensive analysis, several pre-, peri-, and posttransplant variables were explored for possible relationship with the graft function at 3 months and 12 months after parathyroidectomy. In univariable analyses (Table 2) the time interval between transplantation and parathyroidectomy and the serum calcium concentration before parathyroidectomy were not correlated with the eGFR loss $(p=0.183 ; p=0.200)$. Younger age and higher body weight were weakly associated with a greater loss of eGFR ( $p=0.055$ and $p=0.065$ respectively). Male patients had a greater loss of eGFR $(p=0.002)$. Calcification of the renal graft tissue was not linked with a greater loss of eGFR after parathyroidectomy $(-16.45$ $\mathrm{ml} / \mathrm{min}$ compared with $-8.8 \mathrm{ml} / \mathrm{min}$ in patients without calcifications, $p=0.461$ ). Also, severity and frequency of calcification findings were not associated with the loss of eGFR ( $p=0.266$ and 0.589 respectively). Interestingly, we also did not observe an association of the frequency or severity of calcification findings with interstitial fibrosis and tubular atrophy or with arteriolar hyalinosis $(p<0.539$ and $p<0.821)$. Multivariable analysis identified higher eGFR and iPTH values directly before parathyroidectomy 


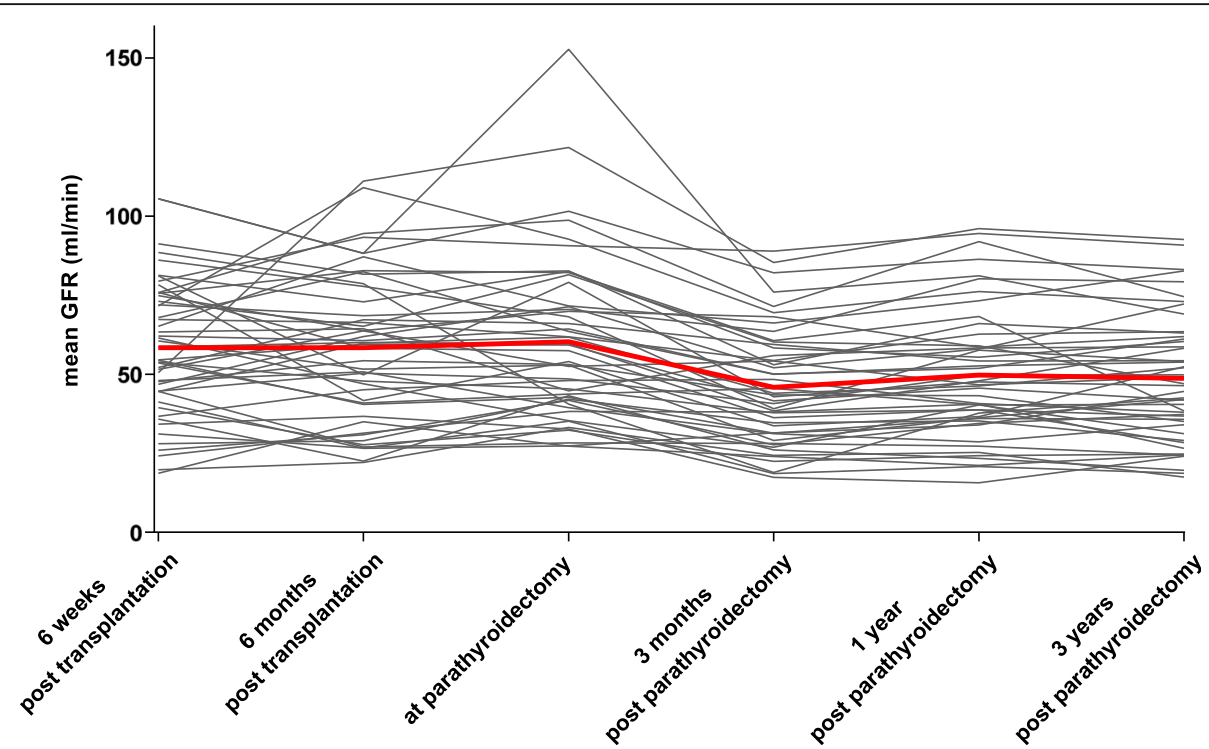

Fig. 4 eGFR before and up to 3 years after parathyroidectomy. Black lines represent individual eGFR values, the red line the mean eGFR. eGFR estimated glomerular filtration rate

as predictors of a greater loss of eGFR at 3 months after parathyroidectomy $(\mathrm{R}=0.625) \quad$ (Table 3a). Alternative models without variable selection or with less stringent cutoffs for selection had lower or not relevantly higher $\mathrm{R}$ values and showed no changes in the $ß$-coefficient of the significant variables (not shown). Variables that were not significant in univariate analyses and not considered in the different multivariable models were shown in an additional file (see Additional file 1).

Recovery from the observed loss in graft function determines the longterm outcome. Therefore, we examined factors which determine the lower graft function one year after parathyroidectomy. In univariable analyses (Table 2), most factors were comparable with the 3 months results, including male gender $(p=0.053)$, body weight $(p=0.078)$, iPTH and eGFR before parathyroidectomy $(p=0.004$ and $p=0.006$, respectively). In addition, the decrease of iPTH after parathyroidectomy was a significant factor $(p=0.011)$. The multivariable analysis (Table $3 \mathrm{~b}$ ) identified higher eGFR before and greater iPTH drop after parathyroidectomy as a predictor of a greater loss in eGFR at 12 months $(R=0.545)$. Similarly, as described above alternative models did not show improved prediction of eGFR.

\section{Discussion}

Persistent Hyperparathyroidism is frequent after kidney transplantation, with approximately $17-50 \%$, mostly occurring as tertiary hyperparathyroidism [1-5]. Tertiary hyperparathyroidism represents a relevant clinical problem due to adverse effects of hypercalcemia in terms of extraosseous calcification and worsening of graft function [1, 6-10]. In this study, the main indications for parathyroidectomy were hypercalcemia which was present in 34 of 48 patients $(71 \%)$ and calcification of the renal graft $(n=31)$. Parathyroidectomy was successful in the majority of patients. Only one patient had to undergo reparathyroidectomy and 3 patients had serum calcium levels above the upper normal value after surgery.

The adverse short-term effect of parathyroidectomy on renal graft function is well-known $[15,16,19]$. We were interested in the longterm graft function of patients with parathyroidectomy and the factors that determine this outcome.

Renal graft function in the whole group of patients appeared to be relatively stable before parathyroidectomy with an eGFR slope of $-0.5 \mathrm{ml} / \mathrm{min}^{*}$ year. This loss is less than reported in studies that analyzed graft function over longer follow-up periods after transplantation, with an annual GFR decline of 1.1-1.7 ml/min [23, 24]. However, most patients were in an early period after transplantation in which gain of graft function is usually observed within the first year (unpublished data). Also, parathormone has been suggested as a driver of glomerular filtration [25-29] which may have obscured a decline in GFR. After parathyroidectomy, a uniform and significant decrease in eGFR by $25 \%$ was observed. This loss of eGFR is greater than reported in other studies showing a $10 \%$ decline in eGFR $[16,19]$. The course of renal function after the initial loss of eGFR is unknown. Our study clearly shows that renal graft function stabilizes in patients with parathyroidectomy. Over the course of three years, the median eGFR was comparable with the eGFR three months after parathyroidectomy. Moreover, individual calculation of the eGFR slope 
Table 2 Correlation of the GFR-change with pretransplant, peri- and posttransplant clinical factors which were considered as candidate variables in the multivariable modeling

\begin{tabular}{|c|c|c|c|c|}
\hline & $\begin{array}{l}\text { eGFR change at } 3 \text { months } \\
\text { post para-thyroidectomy }\end{array}$ & $P$ value & $\begin{array}{l}\text { eGFR change at } 12 \text { months } \\
\text { post para-thyroidectomy }\end{array}$ & $P$ value \\
\hline \multicolumn{5}{|l|}{ Recipient at transplantation } \\
\hline Age & 0.281 & 0.055 & 0.153 & 0.303 \\
\hline Gender (male/female) & $-19.40 ;-8.22$ & 0.002 & $12.93 ;-6.83$ & 0.053 \\
\hline Hyperparathyroidism before transplantation, yes; no & $-14.10 ;-21,54$ & 0.414 & $-10.59 ;-13.93$ & 0.414 \\
\hline Parathyroidectomy before transplantation, yes; no & $-16.87 ;-11.29$ & 0.568 & $-14.78 ;-9.88$ & 0.158 \\
\hline Time on dialysis before transplantation & -0.078 & 0.603 & -0.195 & 0.189 \\
\hline Re-transplanted patients, 2nd or 3rd transplantation; 1st transplantation & $-20.34 ;-11.68$ & 0.372 & $-13.93 ;-10.23$ & 0.535 \\
\hline Body weight at transplantation & -0.277 & 0.065 & -0.265 & 0.078 \\
\hline Body mass index at transplantation & -0.146 & 0.340 & -0.239 & 0.114 \\
\hline \multicolumn{5}{|l|}{ Early post-transplantation course } \\
\hline Delayed graft function, yes; no & $-12.42 ;-16 ; 57$ & 0.924 & $-10.23 ;-11.76$ & 0.505 \\
\hline Best eGFR in the first 6 weeks post- transplantation & -0.542 & $<0.001$ & -0.239 & 0.055 \\
\hline \multicolumn{5}{|l|}{ Post-transplant-related factors } \\
\hline Last serum calcium before parathyroidectomy & 0.190 & 0.200 & 0.290 & 0.048 \\
\hline Mean serum calcium within the first 6 months after transplantation & 0.143 & 0.338 & 0.220 & 0.137 \\
\hline Last serum phosphate before parathyroidectomy & -0.034 & 0.832 & -0.132 & 0.412 \\
\hline Mean serum phosphate within the first 6 months after transplantation & 0.031 & 0.836 & -0.115 & 0.441 \\
\hline Last iPTH before parathyroidectomy & -0.226 & 0.127 & -0.409 & 0.004 \\
\hline Mean iPTH within the first 6 months after transplantation & -0.146 & 0.328 & -0.278 & 0.058 \\
\hline iPTH change after parathyroidectomy & 0.199 & 0.190 & 0.374 & 0.011 \\
\hline Months between transplantation and parathyroidectomy & 0.198 & 0.183 & 0.193 & 0.194 \\
\hline eGFR 6 weeks after transplantation & -0.464 & 0.001 & -0.207 & 0.162 \\
\hline eGFR 3 months after transplantation & -0.524 & $<0.001$ & -0.227 & 0.124 \\
\hline eGFR 6 months after transplantation & -0.373 & 0.010 & -0.129 & 0.386 \\
\hline eGFR 3 months before parathyroidectomy & -0.501 & $<0.001$ & -0.361 & 0.013 \\
\hline Last eGFR before parathyroidectomy & -0.500 & $<0.001$ & -0.398 & 0.006 \\
\hline eGFR change before parathyroidectomy & -0.050 & 0.741 & -0.159 & 0.285 \\
\hline Nephrocalcinosis at biopsy, yes; no & $-16.45 ;-8.8$ & 0.461 & $-11.5 ;-7.9$ & 0.242 \\
\hline Rejections until parathyroidectomy yes; no & $-14.2 ;-10.5$ & 0.749 & $-7.7 ;-11.3$ & 0.701 \\
\hline
\end{tabular}

The change in eGFR 3 months and 12 months after parathyroidectomy was calculated individually for each patient as the difference between the postparathyroidectomy value and the eGFR before parathyroidectomy, with negative values representing a loss of eGFR. PTH change: decrease in iPTH is defined as negative value. Shown are $r$ values for continuous factors and grouped medians for categorical variables. eGFR estimated glomerular filtration rate, iPTH intact parathormone

before and after surgery showed that the eGFR slope changed to positive values after parathyroidectomy, with an average increase of $1.0 \mathrm{ml} / \mathrm{min}^{*}$ year, which could reflect an improvement or recovery after correction of hyperparathyroidism. Yet, because of the substantial initial drop of eGFR, complete recovery of renal function to pre-parathyroidectomy eGFR values was not observed. Despite this incomplete recovery, graft survival and annual eGFR loss over the entire course of 15 years after transplantation was comparable with patients who had no parathyroidectomy after transplantation. Subanalysis of patients with renal graft calcification showed that there is no difference in the initial drop in eGFR after parathyroidectomy and the further course of graft function compared with patients without graft calcification. Due to the lack of systematic re-biopsies we were not able to determine whether calcifications decrease after normalization of the calcium-phosphate metabolism. Also, no systematic study was possible by biopsies performed after parathyroidectomy to associate the functional impairment with histomorphological changes.

Pre-parathyroidectomy parathormone concentration, glomerular filtration rate, serum calcium levels and the time between transplantation and parathyroidectomy 
Table 3 Factors predictive of eGFR loss at 3 (A) and 12 (B) months after parathyroidectomy

\begin{tabular}{|c|c|c|c|c|c|c|}
\hline \multirow{2}{*}{$\begin{array}{l}\text { (A) Model for eGFR loss at } 3 \text { months } \\
\text { Overall fit: } R=0.625\end{array}$} & \multicolumn{3}{|c|}{ Univariable linear regression } & \multicolumn{3}{|c|}{ Multivariable linear backward stepwise regression } \\
\hline & ß & Cl 95\% & $p$ value & B & Cl 95\% & $p$ value \\
\hline Age at transplantation (years) & 0.305 & 0.0380 .573 & 0.026 & & & \\
\hline Female gender & 10.046 & 4.46015 .632 & 0.001 & & & \\
\hline Body weight at transplantation (kg) & -0.205 & -0.4190 .009 & 0.060 & & & \\
\hline Last iPTH before parathyroidectomy (pg/ml) & -0.005 & -0.0130 .002 & 0.165 & -0.006 & $-0,0120.000$ & 0.043 \\
\hline Time between parathyroidectomy and transplantation (months) & 0.114 & -0.0940 .321 & 0.275 & & & \\
\hline Last eGFR before parathyroidectomy (ml/min) & -0.280 & $-0.399-0.160$ & 0.000 & -0.288 & -0.4040 .172 & 0.000 \\
\hline \multirow{2}{*}{$\begin{array}{l}\text { (B) Model for eGFR loss at } 12 \text { months } \\
\text { Overall fit: } R=0.545\end{array}$} & \multicolumn{3}{|c|}{ Univariable linear regression } & \multicolumn{3}{|c|}{ Multivariable linear backward stepwise regression } \\
\hline & B & Cl 95\% & $p$ value & B & $\mathrm{Cl} 95 \%$ & $p$ value \\
\hline Female gender & 4.866 & -0.55610 .288 & 0.077 & & & \\
\hline Body weight at transplantation (kg) & -0.163 & -0.3540 .027 & 0.092 & & & \\
\hline Parathyroidectomy before transplantation & -5.522 & -15.4444 .400 & 0.268 & & & \\
\hline Last iPTH before parathyroidectomy (pg/ml) & -0.008 & $-0.014-0.002$ & 0.016 & & & \\
\hline iPTH change after parathyroidectomy (pg/ml) & 0.007 & 0.0000 .014 & 0.043 & 0.009 & 0.0020 .015 & 0.008 \\
\hline Last serum calcium before parathyroidectomy (mmol/l) & 12.473 & -1.33626 .282 & 0.076 & & & \\
\hline Last eGFR before parathyroidectomy (ml/min) & -0.178 & $-0.296-0.060$ & 0.004 & -0.193 & $-0.304-0.082$ & 0.001 \\
\hline
\end{tabular}

have been proposed as important influencing factors for the eGFR loss after parathyroidectomy. We used the comprehensive documentation of clinical, laboratory and biopsy data of this patient cohort to explore if further factors determine the magnitude of eGFR loss after parathyroidectomy. Our univariable analyses largely confirmed the reported associations and identified only gender as an additional factor. The time point of parathyroidectomy was not a relevant factor in the present time range of 4-80 months posttransplantation. The small number of patients precluded establishing separate models for predicting the eGFR loss in subgroups with different time periods between parathyroidectomy and transplantation. However, univariate sensitivity analyses showed that patients with parathyroidectomy beyond the second year after transplantation had a lower eGFR before parathyroidectomy and a smaller loss of eGFR after parathyroidectomy, compatible with our multivariable model (not shown). Further, neither the univariate analysis (Table 2) nor the multivariable modeling (Table 3) identified the timing of parathyroidectomy as a significant factor. Therefore, parathyroidectomy may be decided at any time when conservative therapy fails and thus an indication for surgical therapy is present. Linear regression analysis showed that the loss in eGFR is significantly determined by the renal graft function and the serum parathormone concentration immediately before parathyroidectomy. The outcome at one year was best predicted by the eGFR before parathyroidectomy and the drop in parathormone by the surgery.

We recognize the limitations of our study which is retrospective and cannot prove causality of the observed associations. Results may not directly applicable to transplant settings in other centers and not to all patients with potential indication for parathyroidectomy as our study included only forty-eight patients.

\section{Conclusions}

Several conclusions can be drawn from our results. First, because the average eGFR loss was $14 \mathrm{ml} / \mathrm{min}$, indication for parathyroidectomy can be considered safe only in patients with an eGFR above $30 \mathrm{ml} / \mathrm{min}$ because otherwise, expected eGFR after parathyroidectomy will be in the range of stage $\mathrm{V}$ of chronic kidney disease. This is important because renal function is a highly significant factor of patient and graft survival $[22,30]$. Second, as the magnitude of iPTH elevation before parathyroidectomy and the drop in iPTH values after parathyroidectomy are major determinants of the loss in eGFR, timely parathyroidectomy -before reaching extreme high iPTH valuesmay be beneficial, thus avoiding the adverse effect of a steep drop in iPTH. Also important in this line, an appropriate extend of parathyroidectomy could help to avoid a steep drop in iPTH after surgery. In our patient group, $23 \%$ of patients experienced hypocalcemia and $23 \%$ had serum parathormone concentrations below the 
lower normal limit, implicating that a substantial proportion probably had an inordinate removal of parathyroid tissue. This point is also highlighted by the fact that one third of patients required calcium supplementation one year after parathyroidectomy and $77 \%$ were treated with vitamin D compounds. Intraoperative $\mathrm{iPTH}$ monitoring could help to avoid an excessive parathyroid tissue removal that can lead to too low iPTH levels after surgery [31].

It should be noted that current guidelines do not give specific recommendations regarding target $\mathrm{iPTH}$ values after parathyroidectomy, the extent of parathyroid tissue removal and its timing after kidney transplantation [3234]. For patients with chronic kidney disease of all stages but without dialysis treatment, iPTH concentrations within the normal range were suggested. Lowering of iPTH values below the lower normal limit as present in a substantial proportion in our patients should be certainly prevented.

\section{Supplementary information}

Supplementary information accompanies this paper at https://doi.org/10 1186/s12882-020-01723-X.

Additional file 1. Correlation of the GFR-change with clinical factors. The table displays the variables that were not significant in univariate analyses and not considered in the different multivariable models.

\section{Abbreviations}

ATG: anti-thymocyte globulin; Cl: confidence interval; CMV: cytomegalovirus; eGFR: estimated glomerular filtration rate; ESRF: end stage renal failure; HLA: human leukocyte antigen; IL-2 AB: interleukin-2 antibodies; IPTH: intact parathormone; SD: standard deviation

\section{Acknowledgements}

Not applicable.

\section{Authors' contributions}

PM, SI and GW collected and analyzed the data. PM, WG and HH designed the study and wrote the paper. All authors read and approved the final manuscript.

\section{Authors' information}

none

\section{Funding}

No funding.

\section{Availability of data and materials}

The datasets used and/or analysed during the current study are available from the last author (Gwinner.Wilfried@mh-hannover.de) on reasonable request.

\section{Ethics approval and consent to participate}

Data collection and analysis was performed with written informed consent of the patients and with approval of the ethic board (no 2765) of the Hannover Medical School.

\section{Consent for publication}

Not applicable.

\section{Competing interests}

The authors declare that they have no competing interests.
Received: 20 October 2019 Accepted: 11 February 2020

Published online: 18 February 2020

\section{References}

1. Copley JB, Wüthrich RP. Therapeutic management of post-kidney transplant hyperparathyroidism. Clin Transpl. 2011;25:24.

2. Evenepoel P, Claes K, Kuypers D, Maes B, Bammens B, Vanrenterghem Y Natural history of parathyroid function and calcium metabolism after kidney transplantation: a single-Centre study. Nephrol Dial Transplant. 2004;19:1281.

3. Jeon HJ, Kim YJ, Kwon HY, et al. Impact of parathyroidectomy on allograft outcomes in kidney transplantation. Transplant Int. 2012;25(12):1248.

4. Santos RD, Rossi A, Coyne D, Maw TT. Management of Post-transplant Hyperparathyroidism and Bone Disease. Drugs. 2019;79:50.

5. Torres A, Redriguez AP, Concepcion MT, et al. Parathyroid function in logterm renal transplant patients: importance of pre-transplant PTH concentrations. Nephrol Dial Transplant. 1998;13(Suppl 3):94.

6. Lou I, Schneider DF, Leverson G, Foley D, Sippel R, Chen H. Parathyroidectomy is underused in patients with tertiary hyperparathyreoidism after renal transplantation. Surgery. 2016;159:172.

7. Gwinner W, Suppa S, Mengel M, et al. Early calcification of renal allografts detected by protocol biopsies: causes and clinical implications. Am J Transplant. 2005:5:1934.

8. Torres A, Lorenzo V, Salido E. Calcium metabolism and skeletal problems after transplantation. J Am Soc Nephrol. 2002;13:551.

9. Mazzaferro S, Pasquali, Tagg F, et al. Progression of Coronary Artery Calcification in Renal Transplantation and the Role of Secondary Hyperparathyroidism and Inflammation Clin J Am Soc Nephrol 2009; 4: 685.

10. Schwarz A, Mengel M, Gwinner W, et al. Risk factors for chronic allograft nephropathy after renal transplantation: a protocol biopsy study. Kidney Int. 2005:67:341

11. Cohen J, Gordon C, Balk E, Francis JM. Cinacalcet for the treatment of hyperparathyroidism in kidney transplant recipients: a systematic review and meta-analysis. Transp J. 2012;94(10):1041.

12. Behets GJ, Spasovski G, Sterling LR, et al. Bone histomorphometry before and after long-term treatment with cinacalcet in dialysis patients with secondary hyperparathyroidism. Kidney Int. 2015;87(4):846.

13. Perrin P, Kiener C, Javier RM, et al. Recent changes in chronic kidney disease-mineral and bone disorders and associated fractures after kidney transplantation. Transplantation 2017; 101(8): 1897.

14. Ivarsson KM, Akaberi S, Isaksson E, et al. Cardiovascular and cerebrovascular events after Parathyroidectomy in patients on renal replacement therapy. World J Surg. 2019;43(8):1981.

15. Schwarz A, Rustien G, Merkel S, Radermacher J, Haller H. Decreased renal transplant function after parathyroidectomy. Nephrol Dial Transplant 2007; 22(2): 584.

16. Evenepoel $P$, Claes $K$, Kuypers DR, Debruyne F, Vanrenterghem $Y$. Parathyroidectomy after successful kidney transplantation: a single Centre study. NDT. 2007:22:1730

17. Lee PP, Schiffmann L, Offermann G, Beige J. Effects of Parathyroidectomy on renal allograft survival. Kidney Blood Press Res. 2004;27:191.

18. Parikh S, Nagaraja H, Agarwal A, et al. Impact of post-kidney transplant parathyroidectomy on allograft function. Clin Transpl. 2013;27(3):397.

19. Littbarski SA, Kaltenborn A, Gwiasda J, et al. Timing of parathyroidectomy in kidney transplant candidates with secondary hyperparathryroidism: effect of pretransplant versus early or late post-transplant parathyroidectomy. Surgery. 2018;163(2):373

20. Jäger MD, Kaaden S, Emmanouilidis N, et al. Effect of incomplete Parathyroidectomy preserving entire parathyroid glands on renal graft function. Arch Surg. 2011;146(6):704.

21. Von Kossa J. Ueber die im Organismus kuenstlich erzeugbaren Verkalkungen. Beitr Pathol Anat Allg Pathol. 1901;29:163.

22. Abeling T, Scheffner I, Karch A, et al. Risk factors for death in kidney transplant patients: analysis from a large protocol biopsy registry. Nephrol Dial Transplant. 2018;1.

23. Marcén R, Morales JM, Fernández-Rodriguez $A$, et al. Long-term graft function changes in kidney transplant recipients. NDT Plus 2010; 3 (Suppl 2): ii2.

24. Weekers L, Vanderweckene P, Pottel H, et al. The closure of arteriovenous fistula in kidney transplant recipients is associated with an acceleration of kidney function decline. Nephrol Dial Transplant. 2017;32:196. 
25. Esbrit $\mathrm{P}$, Santos $\mathrm{S}$, Ortega $\mathrm{A}$, et al. Parathyroid hormonerelated protein as a renal regulating factor. From vessels to glomeruli and tubular epithelium Am J Nephrol. 2001;21:179.

26. Ellison DH, McCarron DA. Structural prerequisites for the hypotensive action of parathyroid hormone. Am J Phys. 1984;246:556.

27. Endlich K, Massfelder T, Helwig JJ, Steinhausen M. Vascular effects of parathyroid hormone and parathyroid hormone-related protein in the split hydronephrotic rat kidney. J Physiol. 1995;483(2):481.

28. Massfelder T, Parekh N, Endlich K, Saussine C, Steinhausen M, Helwig JJ. Effect of intrarenally infused parathyroid hormone-related protein on renal blood flow and glomerular filtration rate in the anaesthetized rat. $\mathrm{Br} J$ Pharmacol. 1996;118:1995.

29. Jespersen B, Randlov A, Abrahamsen J, Fogh-Andersen N, Kanstrup IL. Effects of PTH(1-34) on blood pressure, renal function, and hormones in essential hypertension: the altered pattern of reactivity may counteract raised blood pressure. Am J Hypertens. 1997;10:1356.

30. Morales JM, Marcén R, del Castillo D, et al. Risk factors for graft loss and mortality after renal transplantation according to recipient age: a prospective multicentre study. Nephrol Dial Transplant 2012; 27(S4): iv39.

31. Pitt SC, Panneerselvan R, Chen H, Sippel RS. Secondary and tertiary hyperparathyroidism: the utility of iOPTH monitoring. World I Surg. 2010;34:1343.

32. Ketteler M, Block GA, Evenepoel P, et al. Executive summary of the 2017 KDIGO chronic kidney disease-mineral and bone disorder (CKD-MBD) guideline update: what's changed and why it matters. Kidney Int. 2017;92:26.

33. Moe SM, Drüeke TB, Block GA, et al. KDIGO clinical practice guideline for the diagnosis, evaluation, prevention, and treatment of chronic kidney diseasemineral and bone disorder (CKD-MBD). Kidney Int Suppl. 2009;113:S1.

34. Isakova T, Nickolas TL, Denburg M, et al. KDOQI US commentary on the 2017 KDIGO clinical practice guidelines update for the diagnosis, evaluation, prevention, and treatment of chronic kidney disease-mineral and bone disorder (CKD-MBD). Am J Kidney Dis. 2017;70(6):737.

\section{Publisher's Note}

Springer Nature remains neutral with regard to jurisdictional claims in published maps and institutional affiliations.

Ready to submit your research? Choose BMC and benefit from:

- fast, convenient online submission

- thorough peer review by experienced researchers in your field

- rapid publication on acceptance

- support for research data, including large and complex data types

- gold Open Access which fosters wider collaboration and increased citations

- maximum visibility for your research: over $100 \mathrm{M}$ website views per year

At $\mathrm{BMC}$, research is always in progress.

Learn more biomedcentral.com/submissions 